REVISTA DE DERECHO UNED, NÚM. 21, 2017

\title{
EL TRATADO TRASATLÁNTICO DE COMERCIO E INVERSIÓN: SUS IMPLICACIONES EN EL ÁMBITO DEL DERECHO A LA PROTECCIÓN DE LA SALUD *
}

\author{
THE TRANSATLANTIC TRADE AND INVESTMENT TREATY: ITS \\ IMPLICATIONS IN THE FIELD OF THE RIGHT TO HEALTH \\ PROTECTION
}

Elena Pernas

Abogada, Master en Derechos Humanos-UNED

Doctoranda en Derecho y Ciencias Sociales, UNED

Ana María Marcos

Catedrática acreditada de Filosofía del Derecho-UNED

Resumen: El TTIP es un Tratado Internacional que pretende armonizar las legislaciones, europea y estadounidense, así como rebajar los aranceles y liberalizar los mercados. Prevé también la implantación de un mecanismo de Solución de Controversias entre Inversores y Estados. Sin embargo, existe una total opacidad tanto en las negociaciones como en el articulado, que sólo se conocen por filtraciones. La firma de este Tratado supondrá la privatización de servicios públicos, como la sanidad, el menoscabo de derechos sociales, laborales y ambientales y la pérdida de soberanía por parte de los Estados. El camino de este Tratado comenzó a mediados de la década de 1990, pero no ha sido hasta los últimos diez años cuando las negociaciones han tomado fuerza. Ha generado una gran controversia, lo que ha conseguido retardar su aprobación. En este trabajo queremos poner de manifiesto lo que implicaría su aprobación.

Abstract: TTIP is an International Treaty which claims to harmonize european and american regulations, as well as reducing duties

* Este trabajo está realizado en el marco del proyecto de investigación I + D del Ministerio de Economía y competitividad, DER 2013-41462-R. 
and liberalising markets. It anticipates the implementation of a mechanism of Investor-State Dispute Settlement. However, there is a total opacity both in the negotiations and in the articles, which are known only by leaks. Treaty signature will mean the privatisation of public services, such as health service, the drop of social rights, labours and ambients, and the loss of States sovereignty. The way of TTIP started on 90's, but negotiations did not get strength until last ten years. It generates a huge controversy, which gets to delay its approval. In this paper we want to show what would imply its approval.

Palabras clave: ATCI, comercio, derechos sociales, servicios públicos, sanidad, educación.

Keywords: TTIP, Trade, EU, USA.

Recepción original: 11/09/2017

Aceptación original: 27/10/2017

Sumario: I. Introducción. II. ¿Qué es el TTIP? III. ¿Cuál ha sido el nacimiento y la evolución de las negociaciones? IV. ¿Cómo se debe aprobar el TTIP? V. ¿Qué promete el TTIP? VI. La opacidad del TTIP. VII. El acceso al mercado. VIII. La armonización. IX. ¿Puede afectar el arbitraje internacional a las políticas de salud pública? X. Implicaciones para el Sistema de Salud Público. XI. Repercusiones del TTIP en la política farmacéutica. XII. Principales claves del acuerdo. XIII. ¿Qué riesgos supone para los europeos la aprobación del TTIP? XIV. Un ejemplo práctico: la regulación publicitaria de productos alimentarios. XV. El TTIP en los medios de comunicación. XVI. La respuesta de la ciudadanía. XVII. Conclusiones.

\section{INTRODUCCIÓN}

Los Tratados Internacionales han constituido la base de las relaciones entre los Estados a lo largo de la Historia, en especial en los últimos siglos, si bien no han comenzado a tener una especial relevancia y cumplimiento hasta el final de la Segunda Guerra Mundial. Buen ejemplo de ello es el cambio acontecido en Europa Occidental tras dicho conflicto bélico, donde dos enemigos que se habían producido daños de difícil reparación, Alemania y Francia, pasaron a convertirse en grandes aliados, sumando a ese acuerdo a otros Estados.

No hay que olvidar que dicha Unión se ha producido tomando como base la economía y el comercio, pues, tal y como previó Jean Monnet en 1943, cuando concibió la idea de lo que posteriormente sería la Comunidad Europea del Carbón y del Acero (CECA), «no habrá paz en Europa si los Estados se reconstruyen sobre la base de la 
soberanía nacional [...]. Los países son demasiado pequeños para asegurar a sus pueblos la prosperidad y los avances sociales indispensables...» ${ }^{1}$.

Todo lo avanzado desde ese momento ha girado en torno a temas económicos, quedando un poco rezagada la idea de la Europa de las personas y de los pueblos.

Y, como no podía ser de otro modo en la economía, se producen crisis que provocan un resquebrajamiento de los derechos de los ciudadanos, que son los que sufren las malas decisiones de los gobiernos. Los estragos económicos han provocado que la ciudadanía se encuentre ávida de encontrar nuevas vías que solucionen los problemas a los que ha conducido la crisis económica.

Ante ello, una alianza comercial con los Estados Unidos de América para el crecimiento económico y la inversión parece la solución perfecta. Un pacto con el Estado más poderoso del planeta semeja sólo poseer virtudes, pues debería potenciar el crecimiento económico, la creación de puestos de empleo y el establecimiento de una gran área de intercambio de bienes y servicios.

Pero lo que en principio debería ayudar a Europa a recuperar el terreno perdido, puede no ser lo esperado. Se intenta coaligar dos bloques con demasiadas diferencias y valores en muchos casos opuestos, ya que la sociedad europea es más inclusiva y abierta, compuesta por distintas identidades, con abundantes problemas para llevar a la práctica la parte de «unión». Bruselas es frágil y no existen objetivos comunes, ni, mucho menos, un ideal conjunto, mientras que Estados Unidos parece una máquina muy bien engranada y que aparenta funcionar sin provocar demasiados fallos.

El Acuerdo Transatlántico de Comercio e Inversiones -TTIP, por sus siglas en inglés, Transatlantic Trade and Investment Partnership-, no es el primer Tratado de Libre Comercio por el cual se crea una zona de libre intercambio, es decir, un espacio donde se eliminan las barreras comerciales entre los Estados miembros. Actualmente se encuentran en vigor más de 400, como el NAFTA, MERCOSUR, CETA o el TPP. Si bien estos dos últimos entrarían en la categoría de los Tratados de «nueva generación», en los que destaca con respecto a los anteriores su carácter predominantemente regulador mucho más amplio. Estos Tratados permiten que la regulación del comercio mundial y de la inversión transnacional se independice del control público.

${ }^{1}$ Monnet, J., Los Estados Unidos de Europa han comenzado, Ed. Instituto de Estudios Europeos y Ediciones Encuentro SA, Madrid, 2008, pág. 6. 
Por ello, la relación tradicional entre derecho y política se fractura, ya que la competencia entre los actores económicos se convierte en el mecanismo regulador del mercado global y el control coactivo del nuevo orden mundializado es confiado a instancia supranacionales no democráticas ${ }^{2}$.

El actual peso del comercio en la sociedad ha llevado a lo que será el mayor bloque comercial de mundo, en el cual existirán 820 millones de potenciales consumidores, lo que supone el 60\% del PIB mundial y un tercio de los intercambios mundiales de bienes y servicios ${ }^{3}$.

La aprobación de este Tratado supone establecer un terreno de juego común, aceptando nuevas reglas e intermediarios que estructuren las relaciones a ambos lados del Atlántico, siendo su mayor problema la rendición a los intereses de las grandes multinacionales.

\section{II. ¿QUÉ ES EL TTIP?}

El Acuerdo Transatlántico de Comercio e Inversiones es uno de los denominados Tratados de Nueva Generación, que se está negociando entre la Unión Europea y los Estados Unidos de América, para aumentar el comercio y la inversión entre ambos, pues aspira a propiciar la desaparición de los aranceles que gravan los productos que intercambian ${ }^{4}$.

$\mathrm{O}$, al menos, esa es la información que llega a los ciudadanos a través de las informaciones oficiales y de los promotores del mismo, ya que los aranceles entre Estados Unidos y la Unión Europea son tan bajos que apenas pueden reducirse ya. Según algunas filtraciones que se vienen produciendo, el verdadero objetivo del tratado es eliminar las barreras reglamentarias que limitan los beneficios de las empresas que operan en la Unión Europea y en Estados Unidos, consolidando normas y legislaciones que amparen a los fondos de inversión y a las grandes empresas multinacionales ${ }^{5}$. A ello habría que añadirle la creación de nuevos mercados, abriendo el sector de los servicios públicos y la adjudicación de contratos públicos a esas empresas internacionales, lo que conllevará, irremediablemente, a más privatizaciones en sectores

${ }^{2}$ GuAmán Hernández, A., TTIP: El asalto de las multinacionales a la democracia, Ed. Akal, Madrid, 2015, pág. 23.

${ }^{3}$ Cancela Rodríguez, E., El TTIP y sus efectos colaterales, Ed. Temas de Hoy, Barcelona, 2016, pág. 29.

${ }^{4}$ Taibo ArIas, C., Para entender el TTIP, Ed. Catarata, Madrid, 2016, pág. 16.

${ }^{5}$ VAamonde García, P. (coord.), La salud como negocio, Ed. Laiovento, Santiago de Compostela, 2014, pág. 64. 
como la sanidad o la educación. Para ello se debe eliminar, o al menos relajar la normativa básica en materias como la social y la medioambiental, por las razones que vamos a ir desgranando a continuación.

\section{III. ¿CUÁL HA SIDO EL NACIMIENTO Y LA EVOLUCIÓN DE LAS NEGOCIACIONES?}

El camino del TTIP comenzó hace más de 20 años, en 1995 con la aprobación de la Nueva Agenda Transatlántica, que configuró varias estructuras, denominadas Diálogos para promover la coordinación política y el intercambio entre Estados Unidos y la Comunidad Económica Europea ${ }^{6}$. Precisamente en ese año 1995, se creó el Diálogo Transatlántico (Transatlantic Business Dialogue, en inglés), base a partir de la cual se empezó a gestar el TTIP. Su objetivo era la instauración de un libre mercado transatlántico que impulsara una liberalización mundial de los intercambios comerciales, mediante la unificación de mercados.

En los años siguientes a la aprobación de estos instrumentos, no se produjeron grandes avances, pues existían numerosas dificultades derivadas de las diferencias políticas, administrativas y culturales entre ambos bloques.

Sin embargo, con el inicio del nuevo milenio, y el cambio de estrategia de la Unión Europea al promover las negociaciones de diversos acuerdos bilaterales comerciales de nueva generación, se retomó el camino iniciado en la década de 1990. Es relevante la Comunicación aprobada por la Comisión Europea en 2006, titulada «Una Europa global: competir en el mundo ${ }^{7}$, en la cual se aprecia claramente ese cambio de rumbo, apostando por la bilateralidad, abandonando el proteccionismo y tomando como referencia a los Estados Unidos de América. Las razones de este cambio las podemos encontrar, seguramente, en el surgimiento de una clase capitalista europea que puede influir en las instituciones para sacar un beneficio propio, consiguiendo la reducción de la tutela de los consumidores y de las barreras protectoras internas.

Observamos ese cambio de rumbo en el intento fallido de la aprobación de la Constitución Europea, que si bien no consiguió ser aprobada como tal, sí lo logró el Tratado de Lisboa, que es prácticamente

\footnotetext{
${ }^{6}$ GuAmán Hernández, A., op. cit., pág. 50.

${ }^{7}$ http://eur-lex.europa.eu/legal-content/ES/TXT/?uri=URISERV\%3Ar11022 (consultada el 20/01/2017).
} 
igual. En el Tratado de Lisboa se recoge que la política comercial de la Unión Europea es un campo predominante de su actividad, aunque no debiera de extrañarnos, pues la primera unión que existió, a través de los tres tratados originarios (CECA, CEE y EURATOM) fue de base económica y comercial, y la unión que se ha pretendido siempre lo ha sido desde el punto de vista económico, no teniendo muy en cuenta la partes social y cultural. Por lo que a raíz del Tratado de 2009 comprobamos que se intenta una reestructuración del comercio a favor de la clase capitalista europea emergente que comentábamos.

Precisamente cuando se estaba redactando y aprobando el Tratado de Lisboa, se firmó con Estados Unidos el Acuerdo para avanzar en la Integración Económica Transatlántica ${ }^{8}$, para fortalecer la integración económica, creándose el Consejo Transatlántico Europeo (TEC, en inglés). La conclusión a la que llegó ese Consejo, emitida en el informe publicado el 11 de febrero de 2013, es que la mejor opción era la aprobación de un amplio tratado bilateral que incluyera materia reguladora y pudiera contribuir al desarrollo de normas con impacto global $^{9}$. El día siguiente, en la cumbre del G8, se anunció el inicio de las negociaciones del TTIP.

A partir de ese momento y hasta el día de hoy, se vienen manteniendo las negociaciones entre ambas partes, bajo un gran secretismo, sólo roto por las filtraciones que se han ido produciendo.

\section{IV. ¿CÓMO SE DEBE APROBAR EL TTIP?}

Como hemos indicado, las negociaciones sobre el TTIP se están llevando a cabo sin apenas ofrecer información a los ciudadanos, ni de la Unión Europea ni de Estados Unidos. Si nos atenemos estrictamente a las normas europeas, teniendo en cuenta las modificaciones introducidas por el Tratado de Lisboa, es posible aprobar el Tratado con mayoría cualificada en el Consejo y con mayoría simple en el Parlamento. Lo que excluye la participación de la ciudadanía, tanto directamente a través de un referéndum, como a través de la aprobación en los Parlamentos nacionales, por lo que nos podríamos encontrar con que esas dos Instituciones Europeas aprueben el Tratado sin que se le haya dado ninguna publicidad, como viene ocurriendo hasta ahora.

\footnotetext{
${ }^{8}$ http://ec.europa.eu/DocsRoom/documents/7511/attachments/1/translations/en/ renditions/pdf (consultada el 09/12/2016).

${ }_{9}^{9} \mathrm{http}: / /$ trade.ec.europa.eu/doclib/docs/2013/february/tradoc_150519.pdf (consultada el 29/12/2016).
} 


\section{V. ¿QUÉ PROMETE EL TTIP?}

Desde el inicio de las negociaciones del TTIP, se ha intentado eliminar obstáculos y minimizar cualquier crítica que se le pueda hacer, por lo que desde diferentes lobbies se ha promocionado este Tratado como una panacea, ensalzando los beneficios que conllevaría su aprobación. Pero lo cierto es que esos pseudoestudios son simplemente campañas de márketing encubierto. Podemos poner como ejemplo el elaborado por el $\mathrm{CEPR}^{10}$, que promete un crecimiento económico de un 0,5\% del PIB, un aumento de las exportaciones de un $28 \%$, e incluso, la creación de millones de puestos de trabajo sólo en el lado de la Unión. Pero lo cierto es que el estudio es demasiado optimista, con unas expectativas ficticias y casi imposibles de conseguir a través de este Tratado, pues en realidad se producirá una reducción de las exportaciones, un descenso en el PIB, la pérdida de puestos de trabajo o la merma de ingresos públicos, entre otros ${ }^{11}$.

Como ya han demostrado otros Tratados, como el NAFTA, el crecimiento económico no tiene por qué suponer un aumento del bienestar de la población. Y es que en la situación actual, en el que las desigualdades van en aumento en los Estados que van a formar parte del Tratado, su puesta en marcha puede llevar a la Unión al borde del colapso, pues si se ha producido un maremoto a raíz del "Brexit», no hace falta imaginar demasiado para hacernos una idea de lo que supondría el TTIP: agravamiento de las desigualdades sociales, empeoramiento de los estándares laborales y medioambientales, aumento de las presiones migratorias... Todo ello teniendo en cuenta que no contamos con toda la información necesaria, sino simplemente con los documentos que se han ido filtrando, pues la única oportunidad que tiene este Tratado de salir adelante es sin hacer ruido.

\section{LA OPACIDAD DEL TTIP}

El documento que incluye la autorización para abrir las negociaciones del Tratado y sus líneas maestras, el «mandato de negociación» fue aprobado en julio de 2013, pero no se desclasificó hasta octubre de 2014. En él se recoge que los pilares fundamentales son tres: el

\footnotetext{
${ }^{10} \mathrm{http}: / /$ trade.ec.europa.eu/doclib/docs/2013/march/tradoc_150737.pdf (consultada el 15/01/2017).

${ }^{11}$ GuAmán HernándeZ, A., op.cit., págs. 63 y ss.
} 
acceso al mercado, las cuestiones reglamentarias y barreras no arancelarias y la producción de normas comunes de obligado cumplimiento, incluyendo un mecanismo de solución de controversias inversorEstado $^{12}$.

La razón de la publicación de este documento fue la actuación por parte de la Defensora del Pueblo Europeo en julio de 2014. Y si bien se ha ido publicando cierta información, ni siquiera los europarlamentarios tienen acceso libre a la negociación. Es de sobra conocida la Reading Room, en la cual los europarlamentarios pueden consultar los documentos clasificados, previa firma de un documento de confidencialidad, teniendo prohibido el acceso con cualquier material, siquiera papel y lápiz, siendo vigilados permanentemente por un funcionario. Por lo tanto, la transparencia brilla por su ausencia.

Es muy representativa de esta opacidad la carta de GARCÍA BERCERO, jefe del equipo negociador de la Unión Europea, en la que le aseguraba a su homólogo estadounidense que la Comisión Europea bloquearía el acceso público a todos los documentos relacionados con las negociaciones o el desarrollo del TTIP, no siendo accesibles para el público durante los próximos 30 años ${ }^{13}$.

\section{EL ACCESO AL MERCADO}

El primer objetivo del TTIP es facilitar el comercio de servicios entre la Unión Europea y Estados Unidos, equiparando los niveles de libertad que tienen las empresas para prestar sus servicios en el territorio del otro. Aunque quieran hacer ver que ese comercio se facilita simplemente con la eliminación de los aranceles, esto no es cierto, pues actualmente los pocos existentes son muy bajos.

Hay servicios que quedan excluidos del Tratado, los cuales formarán parte de una lista negativa, en un sistema según el cual todo lo que no esté incluido en la misma será susceptible de ser liberalizado. Además, se pretende aplicar la cláusula «ratchet ${ }^{14}$, que implica que la lista sólo puede ser modificada para introducir medidas menos proteccionistas, y que todo aquello que ha salido de la lista, no puede volver a incluirse. Aunque parece ser que la Unión Europea está pu-

$12 \mathrm{http} / / /$ europa.eu/rapid/press-release_MEMO-13-564_en.htm (consultada el 07/02/2017).

${ }^{13}$ Se puede consultar esta carta en http://trade.ec.europa.eu/doclib/docs/2013/july/ tradoc_151621.pdf (consultada el 23/01/2017).

${ }^{14}$ GuAmán HernándeZ, A., op.cit., pág. 79. 
jando por un sistema mixto, al amparo de una completa lista doble, en la cual se incluirían los sectores susceptibles de liberalización y las excepciones. Pero, a pesar de ello, van a existir numerosas cláusulas secundarias que está previsto que permitan que se registre una fragmentación de esos servicios en virtud de la cual la liberalización podrá afectarles, aplicando, por la puerta de atrás, la parte de la directiva Bolkenstein que no se consiguió aprobar ${ }^{15}$.

Por lo tanto, nos encontramos aquí con el primer problema que puede afectar a los derechos sanitarios de los ciudadanos, pues si un servicio ha sido privatizado, no puede volver nunca más a la esfera pública. Esto supone una amenaza, ya que si un servicio es externalizado o privatizado, aunque sea un desastre y genere unos gastos exorbitados, no se podrá recuperar.

La Organización Médica Colegial española, considera que si la sanidad no es excluida explícitamente del TTIP, podría verse afectada en los ámbitos de salud pública, medicamentos y servicios sanita$\operatorname{rios}^{16}$. Entienden que la mercantilización y la liberalización a que podría dar lugar la firma de ese Tratado, llevaría a la progresiva privatización del Sistema Nacional de Salud.

Y en España, como veremos más adelante, tenemos experiencia en privatizar centros y servicios sanitarios, teniendo que recuperarlos posteriormente, con el gasto que ello supone para el Estado. Lo que se pretende es importar el modelo sanitario de Estados Unidos, basado en el mercado, en el que la salud es una mercancía y no un derecho, sólo al alcance de aquellos que puedan pagarla. Y donde los lobbies manejan a gobiernos y mercados a su antojo, pues representan a miles de empresas que presionan de forma directa para extender sus negocios. Llama la atención que Eucomed, voz de la industria de la tecnología médica europea, se haya entrevistado con responsables de la Unión Europea que forman parte del equipo negociador del TTIP. Aunque no han sido los únicos, pues el lobby de las farmacéuticas o incluso entidades bancarias como el BBVA, también se han reunido.

Pensando en el futuro, en servicios que actualmente no están desarrollados, y no sabemos cómo serán, es legítimo cuestionarse qué ocurrirá con ellos: ¿al no estar incluidos en la lista automáticamente se considerarán como liberalizables?

${ }^{15}$ TAIBO ARIAS, C., op. cit., pág. 52.

16 http://www.cgcom.es/noticias/2015/02/15_02_23_omc_tratado (consultada el 15/12/2016). 


\section{LA ARMONIZACIÓN}

Si bien el principio de armonización es un fundamento interesante en un entorno nacional, e incluso europeo, no podemos dejar de pensar en que es muy difícil armonizar con Estados que tienen una historia y trayectoria diferente a la nuestra. Es el caso de Estados Unidos con respecto a Europa, pues ya sólo a nivel jurídico, ellos se basan en el Common Law, mientras que nosotros aplicamos el Civil Law. Pero no sólo eso, pues existen demasiadas desigualdades entre ambas partes, ya que tenemos modelos sociales, sanitarios, políticos y públicos diferentes, entre muchas otras diferencias.

Podemos suponer que el TTIP va a contribuir a empeorar la situación en Europa, pues creemos que es algo previsible pensar que la armonización de estándares se hará a la baja, degradando las más exigentes, las europeas, ya que es la única manera de conseguir esa liberalización comercial y de inversión que se pretende.

En la Unión Europea existe un principio de precaución que exige hacer pruebas científicas antes de que los productos sean comercializados, para comprobar que no son dañinos para las personas ni para el medioambiente. Mientras que en Estados Unidos es al contrario, la evaluación se hace posteriormente y va acompañada de la garantía de hacerse cargo de las consecuencias de cualquier problema que pueda causar a la salud o al medioambiente. Por lo que este acuerdo podría degradar la regulación europea y abrir el camino a esos productos potencialmente peligrosos sin garantía ninguna para los consumidores europeos.

Dentro de este campo podríamos considerar la contratación pública de servicios de salud a empresas extranjeras, que podrían competir en igualdad con las nacionales, lo cual supondría un perjuicio para las pequeñas y medianas empresas que operan en Europa, así como para los propios Estados que prestan esos servicios públicos, que en muchas ocasiones no podrían entrar en la disputa con esas empresas extranjeras que, para ganar el mercado y conseguir entrar, podrían hacer ofertas temerarias. Además, como consecuencia de todo esto, podría darse el caso de que los contribuyentes financiemos la adquisición de nuestros sistemas de salud por corporaciones extranjeras.

Relacionado con el campo médico, encontramos el farmacéutico, pues a través de este Tratado se pretenden reformar los derechos sobre las patentes, que procura alargar su duración, lo que supone un perjuicio para los pacientes, ya que se tarda más tiempo en lanzar al merca- 
do el medicamento genérico, por lo que, tanto al Estado como a los ciudadanos, les cuesta más dinero la adquisición de esas medicinas.

Un claro ejemplo, y tomando como de nuevo como referencia el NAFTA, en 2012 la farmacéutica Lilly demandó a Canadá ${ }^{17}$, puesto que veía sus beneficios futuros amenazados, basándose en que se producía la "expropiación de sus derechos de propiedad intelectual», solicitando tanto una modificación legislativa como una indemnización millonaria. Algo que puede ocurrir con el TTIP, ya que en ese punto son muy similares ambos Tratados. En el TTIP se pretende conceder a inversores extranjeros el derecho a demandar a gobiernos soberanos frente a Tribunales de Arbitraje ad hoc para la reclamación de pérdidas de los beneficios resultado de decisiones sobre políticas públicas, por lo que ese mecanismo de solución de controversias entre empresas privadas y Estados eleva a las primeras a un estatus equiparable al del Estado nación, amenazando los principios más básicos de la democracia.

\section{IX. ¿PUEDE AFECTAR EL ARBITRAJE INTERNACIONAL A LAS POLÍTICAS DE SALUD PÚBLICA?}

Como acabamos de indicar con el ejemplo de Canadá, existe la posibilidad de que los inversores transnacionales cuestionen y condicionen la legitimidad de los gobiernos en la adopción de normas para la protección de la salud pública.

Este fenómeno del Arbitraje Internacional no es algo nuevo, pues es un instrumento del Derecho Internacional Público denominado en inglés como Investor state dispute settlement (ISDS), en castellano arbitraje de diferencias entre estado e inversor ${ }^{18}$.

Si nos paramos a reflexionar sobre estos casos, podemos llegar a la conclusión de que se rompe el orden jurídico de los Estados, pues supondría atribuir a árbitros un papel similar al del Tribunal Constitucional para la suspensión o anulación de leyes. Por lo que nos encontraríamos en un punto en que se produciría la desaparición de la soberanía de los Estados frente al imperio del libre comercio ${ }^{19}$.

${ }^{17}$ Holguín Zamorano, G., La guerra contra los genéricos, Bogotá, Ed. Aguilar, 2014, pág. 127.

${ }_{18}$ The Transatlantic Colossus, pág. 76. Disponible en http://goo.gl/rP9Lmi (consultada el 01/12/2017).

19 Álvarez-DARDET, C. (coord.), Informe posicionamiento completo SESPAS sobre TTIP y Salud, noviembre de 2015, pág. 16. 
Tanto en el caso de Canadá, como en otros, por ejemplo el de Philip Morris contra Australia y Uruguay, nos encontramos con que no sólo se discute la sentencia de un Tribunal interno, sino también la validez de sus propias leyes, pues al suponerles un perjuicio, pretenden la anulación de las mismas. Lo que rompe completamente con el Estado de Derecho vigente, ya que las leyes son iguales para todos y han de ser aplicadas, excepto en el caso de que el Tribunal Constitucional las anule por ser contrarias a la Constitución. En el fondo, se produciría una injerencia en el principio de legalidad y de soberanía nacional.

En el asunto del modelo de arbitraje de los casos que hemos comentado, y en el que se pretende imponer con el TTIP, existen unos árbitros que conforme a lo que ellos consideren oportuno, dictarán un laudo arbitral, que será de obligatorio cumplimiento para las partes. Lo cual, a todas luces, se muestra como un instrumento pensado estrictamente para garantizar la sumisión de los Estados a las grandes multinacionales, para que en ningún caso vean amenazados sus intereses, sin tener en cuenta en ningún caso a los ciudadanos. A priori, no debería ser una manera inadecuada de resolver un problema. Pero lo cierto es que el mecanismo de arbitraje que propone el TTIP tiene como objetivo favorecer la aparición de un clima favorable a los inversores, permitiéndoles escapar de los tribunales nacionales, pues no se basa en que la empresa es parte del convenio arbitral, sino que se vale simplemente del hecho de que su Estado de origen hubiera firmado un Tratado Internacional con el Estado receptor. Y esta es una vía para actuar fraudulentamente sin respetar la ley, pues las empresas pueden cambiar de nacionalidad con una cierta facilidad, por lo que con cambiar la residencia a otro Estado que haya firmado un acuerdo que les convenga, sería suficiente. Esto mismo fue lo que ocurrió con la compañía canadiense Lone Pine Resources, que cambió su domicilio a los Estados Unidos de América para poder plantear un arbitraje ISDS contra Canadá en el marco del TLCAN (Tratado de Libre Comercio de América del Norte), y de este modo, solicitar un cambio en la moratoria de la fracturación hidráulica (el conocido fracking), dictado por las autoridades de Quebec ${ }^{20}$.

Como ya hemos indicado anteriormente, e incidiendo en ello por ser clave, lo que se pretende a través de este sistema es la protección de la inversión extranjera. Se obligaría a los Estados a darles a los inversores extranjeros un trato igual al que se le da a los nacionales en el establecimiento, adquisición, exploración, gestión, manteni-

${ }^{20}$ Soto DíAz, D. J., "A arbitraxe ISDS. Cando a democracia é un atranco para o capital», en Valdês Paços, B. y Carril Vázquez, X. M. (coord.), O TTIP un cabalo de Troia contra a nosa soberanía, Ed. Laiovento, Santiago de Compostela, 2016, pág. 147. 
miento y venta ${ }^{21}$. Por ello, en España, en donde últimamente se vienen privatizando sectores claves de nuestra economía, esos inversores extranjeros tendrían que ser tratados iguales que los nacionales, y, por lo tanto, nos encontraríamos con empresas extranjeras controlando servicios básicos que conforman las bases de nuestro país.

\section{IMPLICACIONES PARA EL SISTEMA DE SALUD PÚBLICO}

Los acuerdos que se han venido negociando desde 2009 se han centrado en la regulación y armonización de la legislación sobre servicios públicos, su apertura al mercado y el acceso de los inversores privados a los presupuestos públicos, lo que ha supuesto la privatización de muchos de estos servicios ${ }^{22}$.

Precisamente los sistemas públicos de salud europeos sería uno de los mercados que abriría sus puertas de par en par a la entrada de empresas de Estados Unidos. Las sociedades transnacionales intentan de este modo acceder a los jugosos presupuestos sanitarios públicos de los Estados de la Unión Europea, obteniendo así grandes beneficios en un momento en el que están pasando por importantes dificultades para hacer negocios en otros ámbitos.

Los objetivos del TTIP en materia sanitaria están dirigidos a suprimir medidas reguladoras que afectan al comercio eliminando el marco legal europeo y nacional que obliga a la transparencia de los ensayos clínicos de los laboratorios farmacéuticos, minorando las regulaciones ambientales y alimentarias que protegen a consumidores y usuarios, pues en Europa son mucho más estrictas que al otro lado del Atlántico. Además, se pretende incrementar los derechos de propiedad intelectual de las empresas farmacéuticas, alargando los períodos de las patentes de medicamentos e innovaciones tecnológicas, preservando asimismo la inversión de las empresas privadas en los sistemas sanitarios.

\section{REPERCUSIONES DEL TTIP EN LA POLÍTICA FARMACÉUTICA}

Uno de los principales problemas del sistema sanitario español es el gasto farmacéutico. Nuestro gasto en medicamentos es casi el doble

${ }^{21}$ ValdÊs PAços, B., «A Parceria Transatlântica de Comércio e Investimento (PTCI): Mais un passo na mundializaçom», en Valdês Paços, B. y Carril Vázquez, X. M. (coord.), O TTIP un cabalo de Troia contra a nosa soberanía, Ed. Laiovento, Santiago de Compostela, 2016, pág. 24.

${ }^{22}$ VAamonde García, P., op.cit., pág. 65. 
que en el resto de Estados de la Unión Europea. Se ha intentado paliar este gasto a través de diversas medidas como la prescripción de genéricos, la fijación de precios de referencia, la sustitución de medicamentos bioequivalentes para pagar los de menor precio, el copago, etc.

No podemos obviar que el lobby de la industria farmacéutica es uno de los más poderosos del mundo, por lo que es previsible que el TTIP esté diseñado de acuerdo a sus intereses comerciales, pues analizando el acuerdo, vemos que todo es beneficio para estas empresas.

En el acuerdo se prolonga el tiempo de vigencia de las patentes de los medicamentos a más de 20 años, se retrasa la entrada de los genéricos en el mercado, se reducen los requisitos de las patentes para facilitar la comercialización de las innovaciones biotecnológicas, se limitan las políticas de los gobiernos sobre precios y reembolsos, se incluye la presencia de laboratorios en organizaciones estatales para la fijación de precios, se limita la información de los resultados de los ensayos clínicos de nuevos fármacos e, incluso, se plantea la creación de un Comité Industria-Gobiernos para el seguimiento del cumplimiento del acuerdo ${ }^{23}$.

Si se llevan a cabo estas medidas que acabamos de citar, se producirá un incremento del gasto sanitario para los Gobiernos, poniendo en riesgo la sostenibilidad de los sistemas sanitarios públicos, complicando el acceso a los medicamentos por la ciudadanía, incrementando la irracionalidad del sistema y, por supuesto, suponiendo un perjuicio para la salud de la población, lo que conllevará mayores tasas de enfermedades y mortalidad.

Se pretende a través de la aprobación de este Tratado la aceptación de procesos que actualmente están prohibidos en la Unión Europea, como la comercialización de transgénicos o, por poner un ejemplo más peregrino, la desinfección de pollos mediante cloro. Además, se producirán más recortes en educación, formación, desarrollo científico y derechos de propiedad intelectual, esenciales para el avance y la investigación, pues todo quedará en manos de las grandes corporaciones multinacionales. Pero no sólo afectará a este pilar básico del Estado de Derecho, sino como el lector avezado puede intuir a través de estas páginas, al derecho a la protección de la salud, que actualmente goza de las garantías de un derecho social, garantizado por las Constituciones de todos los países europeos, y pasaría a ser una copia del sistema estadounidense, donde los derechos sociales básicos no están garantizados por el Estado.

${ }^{23}$ VAamonde García, P., op.cit., pág. 69. 


\section{PRINCIPALES CLAVES DEL ACUERDO}

Las principales claves del acuerdo ${ }^{24}$ las podemos resumir en:

- Limitación de la soberanía de los gobiernos elegidos democráticamente, facilitando las demandas de las compañías contra las normas y políticas públicas que puedan afectar a sus intereses, como el planteamiento de la reversibilidad de privatizaciones de servicios públicos.

- Apertura a los mercados de sectores esenciales de los Estados europeos, como las patentes, la sanidad pública, la soberanía alimentaria o la energía.

- Desregulación de los servicios financieros, eliminando las restricciones en materia de intercambios financieros y de la distribución de productos financieros derivados (uno de los desencadenantes de la crisis).

- Establecimiento de una regulación financiera que imponga a otros Estados a aceptar y cumplir los estándares que marquen la Unión Europea y Estados Unidos, estando, por tanto, ante una especie de neocolonialismo.

- Desarrollo del «Mecanismo de Solución de Diferencias entre Inversor y Estado» (ISDS), con leyes para proteger la seguridad jurídica de los inversores.

\section{XIII. ¿QUÉ RIESGOS SUPONE PARA LOS EUROPEOS LA APROBACIÓN DEL TTIP?}

Haciendo un resumen de todo lo dicho anteriormente, podemos exponer los siguientes riesgos:

- Vulneración de muchos de los derechos laborales vigentes en Europa, pues Estados Unidos sólo ha suscrito dos de los ocho Convenios Fundamentales de la OIT; además de rebajas salariales.

- Limitación de los derechos de representación colectiva de los trabajadores, ya que al cambiar la localización de las empresas, será más difícil la información y consulta a sus comités de empresa y representantes sindicales.

- Supresión del principio de precaución en materia de estándares técnicos y de normalización industrial.

${ }^{24}$ VaAmonde García, P., op. cit., pág. 64. 
- Privatización de servicios públicos, por el establecimiento de una lista reducida de los que no se pueden privatizar, no pudiendo ser recuperados los servicios que pasen a manos privadas, aunque sea un desastre y suponga un gasto exorbitante.

- Pérdida de derechos sociales.

- Ausencia de sanciones contra los abusos. Normalmente, los Tratados incluyen un capítulo dedicado al desarrollo sostenible, en el cual se recogen mecanismos de resolución de conflictos y sanciones en caso de violación, lo que no existe en el TTIP.

- Sumisión de los Estados a un «Derecho especial» hecho a medida para las multinacionales, a través de un mecanismo de arreglo de diferencias entre Estados y empresas, al margen de los tribunales nacionales de justicia.

Pero todos estos riesgos que hemos venido enumerando, no terminarían eventualmente aunque el Tratado se llegara a rescindir por alguna de las partes, pues, por ejemplo, el mecanismo de arbitraje podría seguir surtiendo efectos durante años. Sin ir más lejos, el CETA (Comprehensive Economic and Trade Agreement), el acuerdo de libre comercio con Canadá, precursor y prácticamente hermano del TTIP, en vigor desde febrero de $2017^{25}$, incluye la denominada cláusula $z_{\text {zombie }}{ }^{26}$ para que en el caso de que el Tratado deje de estar en vigor, el ámbito de la protección de la inversión siga viviendo. En su artículo 30.9.2), establece que en caso de finalización del Tratado, las disposiciones del capítulo referido a las inversiones seguirán siendo efectivas durante veinte años a partir del fin del Tratado.

Este hecho llama la atención, y es que conforme a nuestro Derecho, si una norma se deroga por otra, la primera deja de tener efectos. Pero, tal y como se plantea en el párrafo anterior, podría darse el caso de que el Tratado dejara de estar en vigor y derogado, y aún así seguiría surtiendo efectos.

\section{UN EJEMPLO PRÁCTICO: LA REGULACIÓN PUBLICITARIA DE PRODUCTOS ALIMENTARIOS}

Aunque se haya intentado explicar de una manera sencilla los problemas que conllevaría la aprobación del TTIP, parece interesante

\footnotetext{
${ }^{25}$ https://elpais.com/internacional/2017/02/15/actualidad/1487152751_668517.html (consultado el 28/07/2017).

${ }^{26}$ ValdÊs Paços, B., op. cit., pág. 31.
} 
aportar un ejemplo práctico, basándonos en cómo las grandes empresas intentan, y a veces consiguen, imponer sus intereses.

Las grandes multinacionales, como ya hemos visto, son capaces de enfrentarse a los Estados, para conseguir mayores beneficios. A través de grandes campañas de marketing venden sus productos, aunque lo que publicitan no sea cierto al $100 \%$, como es el caso de los alimentos funcionales ${ }^{27}$.

En la Unión Europea, se creó en 2002 la Autoridad Europea de Seguridad Alimentaria (EFSA), para garantizar un alto nivel de protección de los consumidores y aumentar la confianza en el suministro de alimentos ${ }^{28}$, pues hasta ese momento existía un cierto vacío legal, por lo que las empresas tenían vía libre para publicitar todo lo que desearan sin ningún control. Incluso se han publicitado eslóganes de alimentos que decían "favorece el desarrollo del sistema inmune», «baja la tensión arterial» y hasta "previene el cáncer» ${ }^{29}$, sin que dichos reclamos tuvieran base científica alguna. Por ello, se elaboró el Reglamento CE 1924/2006, relativo a las declaraciones nutricionales y de propiedades saludables en los alimentos y el Reglamento CE $353 / 2008$ por el que se establecen normas de desarrollo para las solicitudes de autorización de declaraciones de propiedades saludables, modificado por el Reglamento CE 1169/2009. Una vez entrado en vigor el primero de los Reglamentos, al realizar las evaluaciones de las solicitudes que habían realizado miles de empresas para poder publicitar sus productos conforme a la nueva normativa, unos 44.000, sólo se aprobaron $222^{30}$, siendo el resto rechazadas por diferentes motivos. Actualmente, la denegación de solicitudes es la norma habitual. Por lo tanto, se puede llegar a la conclusión de que hasta ese momento el consumidor estaba siendo engañado, e incluso, que podría ser perjudicial para su salud (no hay más que pensar que si un cierto producto previene el cáncer, habrá personas que abusen del mismo para no padecerlo).

A nivel español nos encontramos con lo acontecido a principios de la década de 1990 con el etiquetado de los productos «Eco» y "Bio», referidos ambos términos a aquellos productos elaborados bajo los sistemas de producción ecológica ${ }^{31}$. La gran industria alimentaria presionó para que el término «Bio», que en toda Europa se limitaba

${ }^{27}$ LÓPez Nicolás, J. M., Vamos a comprar mentiras, Ed. Cálamo, Palencia, 2017, pág. 22 y ss.

${ }^{28}$ Ibídem, pág. 27.

${ }^{29}$ Ibídem, pág. 28.

${ }^{30}$ Ibídem, pág. 31.

${ }^{31}$ Ibídem, pág. 57. 
ese tipo de productos, en España fuera posible usarlo para todo tipo de alimentos. Y lo consiguieron. En el año 2001 se aprobó el RD 506/2001 por el cual se extendía el uso del prefijo y calificativo «Bio» a todos los productos alimenticios, fueran de agricultura o ganadería ecológica o no, basándose en que los consumidores no asociaban ese término a ese tipo de agricultura. Pero la Comisión Europea obligó a España, tras una gran resistencia por parte de la gran industria alimentaria y del propio Gobierno en el año 2007, teniendo que aprobar el Consejo un nuevo Reglamento, el CE 834/2007, sobre producción y etiquetado de productos ecológicos por el que se volvía a la situación anterior, pudiendo aplicarse solamente los términos «Bio» $\mathrm{y}$ «Eco» a los procedentes de la agricultura y ganadería ecológicas ${ }^{32}$.

En esta misma época, siete importantes empresas multinacionales crearon la Global Alliance for Probiotics ${ }^{33}$, para, entre otros, defender sus intereses por considerar que la EFSA les atacaba. Lo que se denominaría como lobby alimentario, para luchar juntas contra, en este caso, una Institución Europea. Con el tiempo se ha visto que no ha tenido el efecto esperado, pues la EFSA no ha cedido a sus presiones.

Pero la pregunta que debemos formularnos en este momento es: ¿cómo podría el TTIP hacer que esto cambiara? Como ya se ha indicado arriba, con la aprobación de este Tratado, las grandes multinacionales podrían ser capaces de modificar la legislación interna de los Estados e incluso la de la propia Unión Europea, por lo que podría darse el caso de que la lucha de la EFSA por defender los derechos, y la salud, de los consumidores haya sido en balde. A través del sistema de Arbitraje, podrían demandar al Estado o a la Unión Europea para que modificara esas normas por serles perjudiciales, poniendo en grave peligro a los ciudadanos.

Otro ejemplo relacionado sería el de la Ley 3/1991, de 10 de enero, de Competencia Desleal, que en su artículo 5.1 recoge que «se considera desleal por engañosa cualquier conducta que contenga información falsa o información que, aun siendo veraz, por su contenido o presentación induzca o pueda inducir a error a los destinatarios, siendo susceptible de alterar su comportamiento económico...». Con el TTIP, esta norma podría ser modificada y dejar vía libre a las grandes multinacionales rompiendo de ese modo el derecho de información de los consumidores.

\footnotetext{
${ }^{32}$ Ibídem, pág. 58.

33 Ibídem, pág. 41.
} 


\section{EL TTIP EN LOS MEDIOS DE COMUNICACIÓN}

Sería lógico pensar que ante un Tratado que es tan perjudicial para la ciudadanía como el TTIP, estuviera apareciendo continuamente en los medios de comunicación, tanto públicos como privados. Pero lo cierto es que esto no ocurre, pues parece más bien que quieren tapar todos sus inconvenientes y perjuicios, haciendo ver que estamos ante uno más de tantos Tratados que firman los Gobiernos pensando en nuestro bienestar.

Todo aquel que quiera informarse a través de la prensa sobre el TTIP, se va a encontrar con que los grandes medios simplemente ignoran el tema, intentando que pase desapercibido. Ésta ha sido la estrategia de los grandes medios con el TTIP, hasta que se han producido las filtraciones de Greenpeace.

Pero a raíz de dicho suceso, lo que ha ocurrido es que los medios se han dedicado a desprestigiar a los activistas que son contrarios a dicho Tratado. Sirvan como ejemplo los siguientes:

— «El tratado de libre comercio entre la UE y EEUU resucita el discurso antiglobalización», en El País el 02/05/2016.

— «El TTIP convivirá con otros tratados para convertir al planeta en grandioso mercado común», en El País el 06/05/2016.

— «EEUU no está contento con la filtración de documentos del TTIP», en El País el 08/05/2016.

— «Paranoias antiliberales: el TTIP», en Expansión.com el 10/05/2016.

— «Le Pen y la ultraderecha europea piden el cese inmediato de las negociaciones del TTIP», en El Economista.es el $11 / 05 / 2016$.

Estos son sólo algunos de los titulares de importantes medios de comunicación españoles. Se puede observar que se intenta tachar la antiglobalización como algo perjudicial, que el TTIP será beneficioso para todos, que EEUU «se enfada» y eso no conviene a Europa, que hay que ser un "paranoico» para no ver las bondades del TTIP o que sólo la ultraderecha está en contra.

Se puede comprobar, por tanto, el intento de manipulación de los medios de comunicación sobre la opinión de la ciudadanía acerca de este Tratado, tratando de dirigirla hacia un punto en el que esté a favor, aunque le vaya a perjudicar. 


\section{LA RESPUESTA DE LA CIUDADANÍA}

La Declaración de Barcelona ${ }^{34}$, firmada en esa misma ciudad el 21 de abril de 2016, dentro del Encuentro Paneuropeo de Autoridades Locales y la Nueva Generación de Tratados de Libre Comercio, recoge que el TTIP, el TISA y el CETA son tratados que están siendo negociados de manera poco transparente, incumpliendo los estándares democráticos y participativos europeos. En este documento se reconoce el hecho de que estos Tratados no son beneficiosos para la sociedad, por lo que las negociaciones deben ser suspendidas, iniciándose de nuevo bajo el mandato de toda la sociedad. Aunque para el último ya es tarde, pues ya ha sido aprobado.

Lo cierto es que dicha Declaración no ha sido conocida por la mayoría de la ciudadanía, pues apenas tuvo publicidad cuando se firmó, por todos los intereses que hemos puesto de manifiesto en epígrafes anteriores.

Pero, a pesar de ello, en muchas Comunidades Autónomas, Diputaciones y Ayuntamientos se han firmado mociones en contra del TTIP. En 10 Comunidades Autónomas, en 9 Diputaciones Provinciales y en 193 Ayuntamientos desde mediados del año 2014. Se vienen produciendo numerosos actos y manifestaciones de la ciudadanía en contra del TTIP, pero, debido al silencio informativo por parte de los medios de comunicación públicos y privados, parece que toda la población está de acuerdo con dichos Tratados, pues lo que no se ve, no existe.

\section{CONCLUSIONES}

Por todo lo dicho, podemos afirmar, sin temor a equivocarnos, que el TTIP no debe entenderse como un acuerdo entre dos socios comerciales competidores, sino como un asalto a la sociedad europea y a la estadounidense por parte de las corporaciones transnacionales con el objeto de abrir y desregular mercados a ambos lados del Atlántico en su propio beneficio ${ }^{35}$.

Uno de los principales objetivos del Tratado es universalizar la privatización de los servicios sanitarios, que son contemplados por

${ }^{34}$ http://www.noalttipág.org/wp-content/uploads/2015/10/Declaracio\%CC\%81-final-amb-esmenes.-CAST.pdf (consultado el 20/02/2017).

${ }^{35}$ Hilary, J., El acuerdo transatlántico sobre comercio e inversión, noviembre de 2015, Rosa Luxemburg Stiftung, Oficina de Bruselas, pág. 24. 
los inversores privados y por la industria farmacéutica como un gran y beneficioso mercado. De hecho, la Comisión de Comercio de la Unión Europea acordó en 2010 presionar para llegar a un acuerdo comercial que armonizase la regulación del sector público europeo con el estadounidense, incluyendo la asistencia sanitaria por su importancia económica, lo que debería dar lugar a su privatización, tal y como es el sistema en Estados Unidos ${ }^{36}$.

Este Tratado pretende crear nuevos mercados para la inversión privada, traspasando recursos del sistema sanitario público al privado.

Lo cierto es que en nuestro país, este no es un hecho novedoso, pues en los últimos años se han ido dando pasos en este sentido, como a través de la Ley 15/1997, de 25 de abril, sobre habilitación de nuevas formas de gestión del Sistema Nacional de Salud, por la cual la gestión de los servicios sanitarios podía ser privatizada a través de la financiación público-privada para la construcción de centros sanitarios con la externalización de servicios. Y ello sin olvidar el intento de implantación de las Unidades de Gestión Clínica, que transformarían los servicios en empresas que competirían entre sí, con presupuestos propios y capacidad para comprar y vender, introduciendo la lógica empresarial en la asistencia sanitaria. Si al final se consiguiera implantar este sistema, con el TTIP sería imposible dar marcha atrás en ese modelo.

En el momento histórico en el que nos encontramos, en el que el número de preguntas que nos planteamos es cada vez menor, por la alienación a la que se ve sometida la mayoría de la sociedad, tratar de poner sobre la mesa un debate público de calidad es prácticamente misión imposible. Asumir dogmas nos ha llevado a un «coma» del que parece que nunca despertaremos.

Y aunque la ciudadanía se encuentre en ese estado, no debería ser descabellado pensar que al menos nuestros representantes deberían exigir cuentas a una Europa que cada vez se encuentra más lejos de los principios básicos de la democracia. Pero ello no ocurre porque implica un coste político que ninguno está dispuesto a pagar. El trabajo de ofrecer un cambio a la sociedad corresponde a aquellos que sean capaces de liderarlo. Prácticamente nos hallamos en ese punto de no retorno en el que sólo hay resignación y odio contra los responsables. Pero precisamente pensar simplemente en el declive, es lo que impide que nada cambie.

${ }^{36}$ VAAMONDE García, P., op.cit., pág. 67. 
No podemos obviar que el acuerdo transatlántico establecerá un escenario que provocará cambios en todos los ámbitos de la vida diaria de las personas. Se pretende que la disciplina económica predomine a la hora de tomar una decisión política. Las empresas adquirirán más derechos al mismo que pierden obligaciones y se crearán órganos burocráticos supraestatales que restan poder a los Parlamentos, acorralando la toma de decisiones democráticas mediante disposiciones legales que si los ciudadanos no se encontraran en situación de aletargamiento, considerarían inaceptables.

Aún estamos a tiempo de parar esta insensatez desde el punto de vista jurídico, político y social, pero para ello es necesario que ceje la opacidad, se conozcan las implicaciones de la firma de este Tratado en los derechos fundamentales y salga a la opinión pública este debate. Pues, de lo contrario, el final de esta historia será muy negro para una gran parte de ella. 